\title{
RAPID CORRECTION OF CONSTRICTED MAXILLARY ARCH IN A CLASS III PATIENT USING A CORTICOTOMY ASSISTED EXPANSION TECHNIQUE
}

\section{Roni R Kuttickal, Goutham Reddy, Sunil Muddaiah, ${ }^{3}$ Balakrishna Shetty, ${ }^{4}$ Sanju Somaiah, ${ }^{5}$ Manu Mathew.}

1. Post Graduate Student, Department of Orthodontics, Coorg Institute of Dental Sciences, Coorg, Karnataka, India.,

2. Professor and Head, Department of Orthodontics, Coorg Institute of Dental Sciences, Coorg, Karnataka, India.

3. Professor, Department of Orthodontics, Coorg Institute of Dental Sciences, Coorg, Karnataka, India.

4. Professor, Department of Orthodontics, Coorg Institute of Dental Sciences, Coorg, Karnataka, India.

5. Professor, Department of Orthodontics, Coorg Institute of Dental Sciences, Coorg, Karnataka, India.

6. Post Graduate Student, Department of Orthodontics, Coorg Institute of Dental Sciences, Coorg, Karnataka, India.,

\section{Corresponding Author :}

Roni R Kuttickal.

Department of Orthodontics and Dentofacial Orthopaedics

Coorg Institute of Dental Sciences

Virajpet, Coorg, Karnataka

India, 571218

Contact number-+9497321203,

E-mail ID: ronikuttickal@gmail.com

Submitted Date :02-02-2020

Accepted Date :07-02-2020

\begin{abstract}
This case report introduces a noval approach of corticotomy-assisted rapid maxillary expansion for treating a severe maxillary transverse discrepancy in an adult patient. This approach uses piezo-bone perforation in conjunction with a fixed appliance and expanded jockey arch wire. This report describes the treatment of an 18-year-old male with a severe maxillary transverse discrepancy. He had a straight profile, mild maxillary crowding, severe maxillary transverse deficiency and a Class III skeletal relationship. The treatment protocol commenced with active orthodontic therapy, after leveling and aligning surgical intervention with Piezocision assisted bone perforation was performed. Immediately after the piezo assisted bone perforation on bilateral buccal side of the maxilla, active expansion force was given with expanded jockey arch wire. The expanded jockey wire was left in place for 3 months. Proper overbite and overjet, facial balance, and occlusion were achieved. The case is in final stage of finishing. This treatment approach considerably reduced the treatment time and gained bony volume. This approach is a good alternative to surgical rapid palatal expansion for treating a severe maxillary transverse deficiency in an adult patient.
\end{abstract}

Key words: Corticotomy, osteotomy, accelerated orthodontics, Piezocision 


\section{INTRODUCTION}

Maxillary transverse discrepancy is a common anomalyseen in patients seeking orthodontic treatment. Transverse deficiency is frequently defined as a unilateralor bilateral crossbite combined with anterior crowding. Treating a posterior cross bite in adults is challenging. Approaches available to treat transverse discrepancyare numerous and includes rapid maxillary expansion (RME), slow maxillary expansion (SME), and surgically assisted rapid palatal expansion (SARPE). Treatment often depends on the patient'sskeletal maturity, ${ }^{4}$ The amount of desired expansion, 5 and the presence of a concomitant sagittal or vertical problem. RME and SME are successfully used in growing patients, whereas in skeletally mature patients procedures like SARPEor MARPE isthe treatment of choice. Several authors have comparedthe treatment outcomes and concluded that their effectiveness is similar. ${ }^{7,8}$ However, it has been reported thatperiodontally undesirable effects, long duration oftreatment, and invasiveness are disadvantages of SARPE. ${ }^{9,10}$ Several authors ${ }^{9,11}$ demonstrated bone loss after RMEwith both hyrax and Haas expanders. Because of these reasons, most orthodontists think twice before usingthese treatments for patients with a thin periodontium.Meanwhile, corticotomy was introduced in orthodontics as an alternative treatment option for maxillarytransverse discrepancy. Kole ${ }^{12}$ 1959, followed by Converse and Horowitz ${ }^{13}$ in 1969 respectively were the first to use corticotomy in orthodontics. Lines also łeported maxillary expansion with the use of corticotomyin 1975. Wilcko et $\mathrm{al}^{15-17}$ reintroduced the concept in the beginning of $21^{\text {st }}$ century and named the technique "accelerated osteogenic orthodontics"; it is also called as "periodontally accelerated osteogenic orthodontics."All authors argued that the severity of the maxillary transverse discrepancy should be considered before choosing the desired expansion technique. They further stated that the treatment is indicated for mild-to-moderate transverse discrepancies. Until now, many studies have been published on severe maxillarytransverse discrepancies and severe crowding treatedwith a corticotomy including corticotomy-assisted RME to overcome the limitationof expansion using surgical and severe invasive techniques in skeletally mature patients.Such approachesthat involves theuse of piezo-bone perforation withfixed appliances and expanders ${ }^{18}$ are benchmark studies for further development ofthese techniques.

\section{CASE REPORT}

An 18-year-old male patient presented to the orthodontic clinic with a chief complaint of crooked teeth and unpleasant smile. His medical and dental histories were insignificant. He was well motivated and demonstrated a good standard of oral hygiene. Extra-oral examination (Figure 1) revealed a Class III pattern with a straight profile and average nasolabial angle and prominent chin. His facial symmetry was acceptable and balanced, with an increased lower vertical proportion. Examination of the soft tissue demonstrated competent lips.
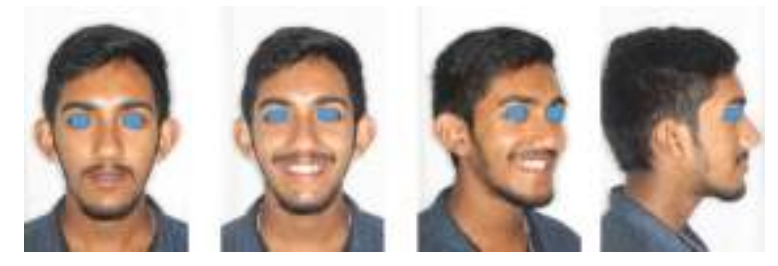

Fig 1.Pretreatment Extraoral Images

His Intraoral examination shows (Figure 2) posterior gingival display on smiling. The upper midline was deviated by $1 \mathrm{~mm}$ to the right of the facial midline, and the lower midline was deviated by $2 \mathrm{~mm}$ to the left of the upper midline. Dentally, she had Class I canine relationship with mutilated molar relation because of missing 36 . An overbite of $1 \mathrm{~mm}$, a deep curve of Spee, and an exaggerated compensating curve. There was mildcrowding in upper anterior segment he also had bilateral posterior crossbiteand lateral incisor crossbite on upper left side.

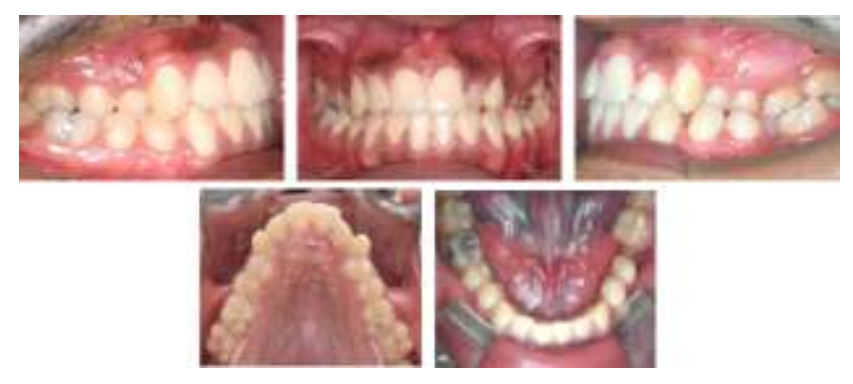

Fig 2. Pretreatment Intraoral images

Pretreatment panoramic radiograph (Figure 3) showed missing 36. 37 has tipped mesially slightly to the extraction space, All 4 third molars were present. The patient had fillings, on 46,26 and no periodontal defects. 


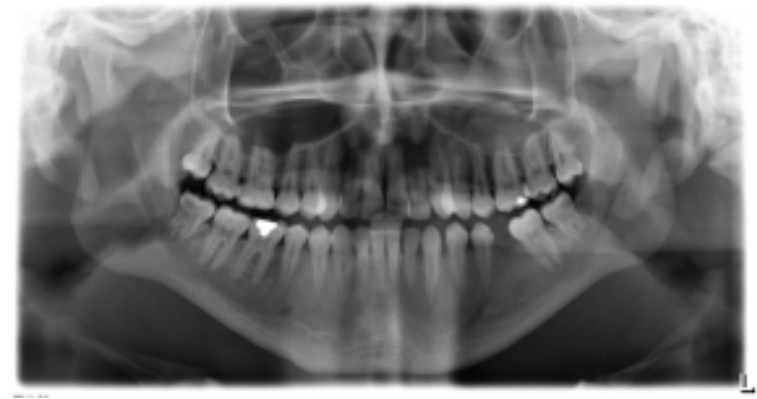

Fig 3.OPG

Pretreatment Cephalo metric evaluation (Figure 4)(Table 1) showed, a skeletal Class III relationship ( $\mathrm{AO}$ to $\mathrm{BO}=-3$ ) with maxillary retrusion (SNA angle, 75) was observed. The mandibular plane angle was high (GoGn-SN, 40). The position of the maxillary incisors was severely proclined (U1-Na, 42), but the mandibular incisors were lingually inclined (IMPA, 81), The lateral cervical vertebrae on the cephalo metric radiograph showed that the patient had passed her growth peak. Mandibular plane angle (25) showed average growth pattern.

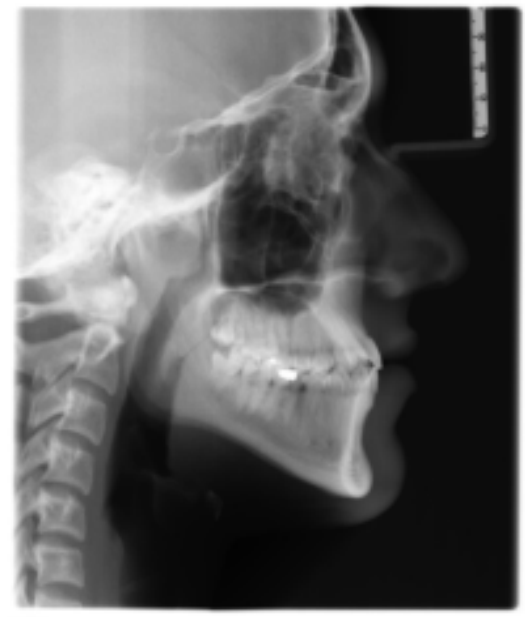

Fig 4. Lateral Ceph

\begin{tabular}{|c|c|c|}
\hline CEPHYALTS & NORMt & FETREEATMENT \\
\hline Sx. & $F$ & 3 \\
\hline avo & $F$ & 3 \\
\hline 20าอง & Tour nat & $=$ \\
\hline 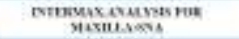 & nid & 7 \\
\hline sux sucess-7 & Assons & $3 \times(5)=$ \\
\hline 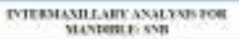 & $m a r$ & $\pi$ \\
\hline navsimsx-tien & $\cos \pi$ & 810039 \\
\hline wh nasucosm & $\cos \theta$ & 119 \\
\hline su & 5 & 12 \\
\hline 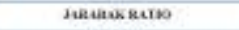 & neas & $a n$ \\
\hline 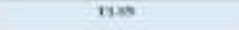 & wer & 100 \\
\hline$\omega \times x$ & Iram & $40 \%$ \\
\hline tiver & * & $\mu$ \\
\hline 140 & 15. атм & 153 \\
\hline 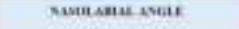 & nes: & 100 \\
\hline Mevtroukast Avat & maim & 100 \\
\hline
\end{tabular}

Table 1. Pretreatment ceph values

\section{TREATMENT OBJECTIVES}

The treatment objectives were to resolve the maxillary transverse deficiancy by expanding the maxilla,correct the anterior crossbite, obtain ideal overjet and overbite, provide canine guidance in lateral excursions and incisal guidance in protrusive movements, correct the midline discrepancy, obtain Class I dental relation-ships in the canines and molars, Replace 36 prosthetically and improve the patient's appearance

\section{TREATMENTALTERNATIVES}

4 options were examined.

The optimal option was SARPE with fixed orthodontic appliances. It was the treatment of choice because of the high maxillomandibular differential transverse index. However, the patient and her parents did not want this option because of the costs and invasiveness. The second option relied only on orthodontic treatment with RME and fixed appliances it was avoided because this option can cause detrimental effects on the periodontium hence it was avoided. The third option also depended only on orthodontic treatment with SME and passive self-ligating appliances but the long treatment time deterred the patient from choosing this option. The last option was a corticotomy-assisted RME with expanded jockey arch wire the patient wanted to finish the treatment quickly with the safest approach to peridontium this option was chosen.

\section{TREATMENT PROGRESS}

Preadjusted edgewise metal brackets (Koden silver series 0.022-in slot;) were bonded on both arches, and initial alignment was done with 0.014 and 0.018 nickel-titanium arch-wires(Figure 5). After alignment Impression was made, jockey arch wire was fabricated with $1 \mathrm{~mm}$ round ss wire with $3 \mathrm{~mm}$ expansion on all sides. Following this corticotomy was performed under local anesthesia vertical incisions were made on right and left buccal mucosa, and then a piezo-surgical device ( Woodpecker US II ) was used through this vertical incisions on both lateral sides of the maxilla The depth of the piezo-perforations varied between 0.5 and $1.5 \mathrm{~mm}$, dependingon the width of the alveolar crest.

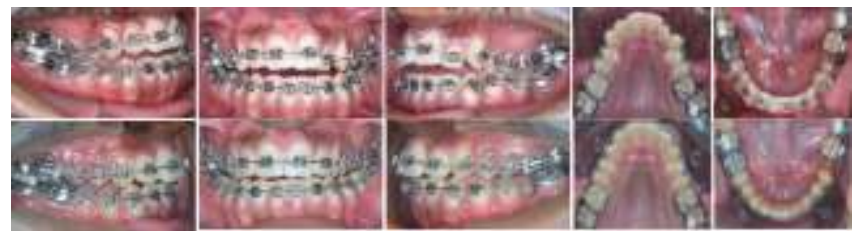

Fig 5. Leveling and Aligning 
(Figure 6) The incisions were sutured, Immediately following this a base arch wire of 0.018 special plus AJ wilcock wire was placed in the maxillary arch and ligated with stainless steel ligature, over this $1 \mathrm{~mm}$ jockey wire was engaged into the head gear tube of the molar and ligated into place over the base arch wire (figure 7).
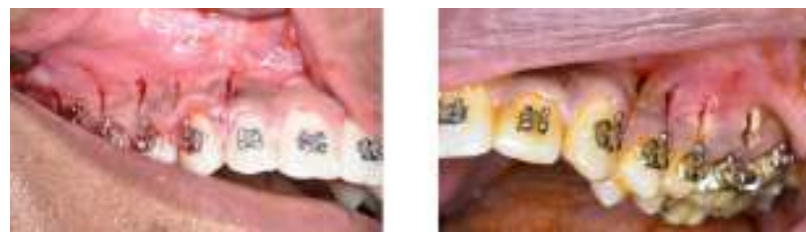

Fig 6. Corticotomy

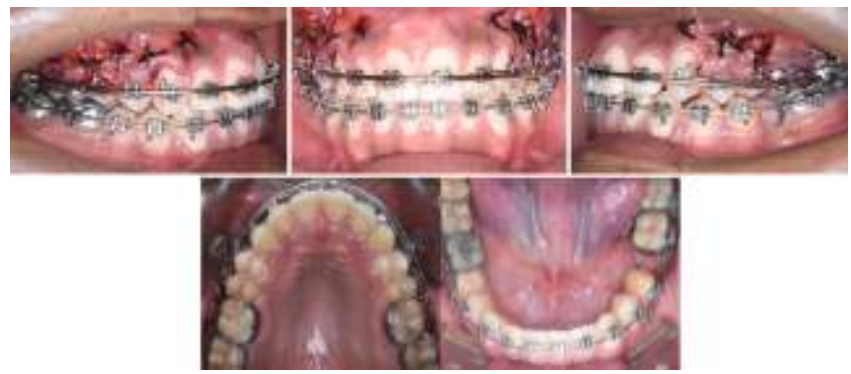

Fig7. Engagement of Jockey arch wire

An $0.018 \mathrm{NiTi}$ wire was engaged in the lower arch .Antibiotics and analgesics were prescribed. Home-care and hygiene instructions were given to the patient after 6 to 10 weeks of placement remarkable improvement in the transverse dimension was noted(figure8). Over expansion was done to over correct the crossbite. The patient currently is in finishing stage with correction of midline (figure 9).

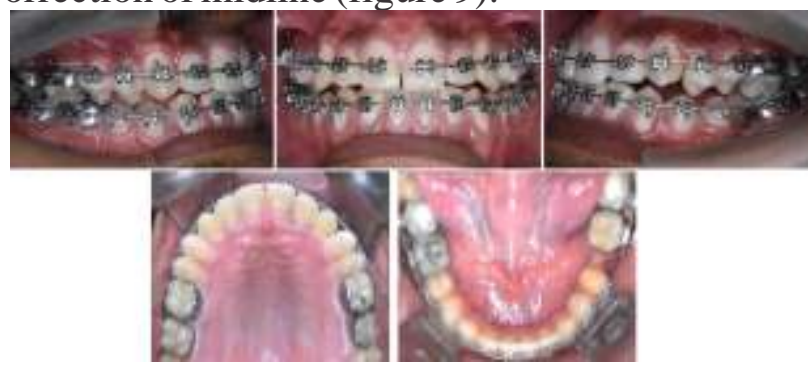

Fig 8. Post expansion images

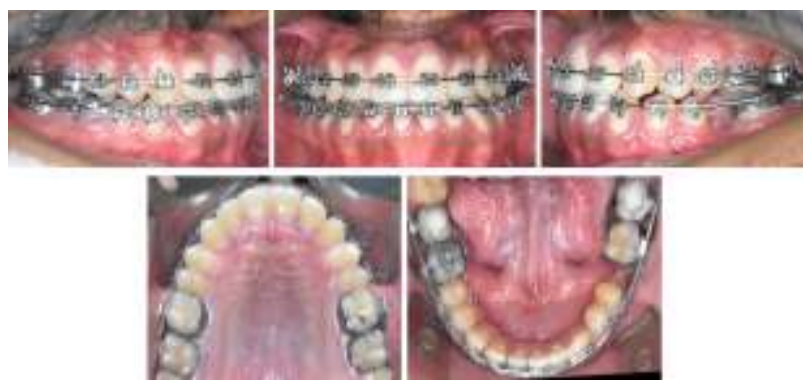

Fig 9. Midline correction
After finishing the treatment Beggs wraparound retainers will be given forretention. The difference in the gain of transverse expansion is remarkable (Figure 10)
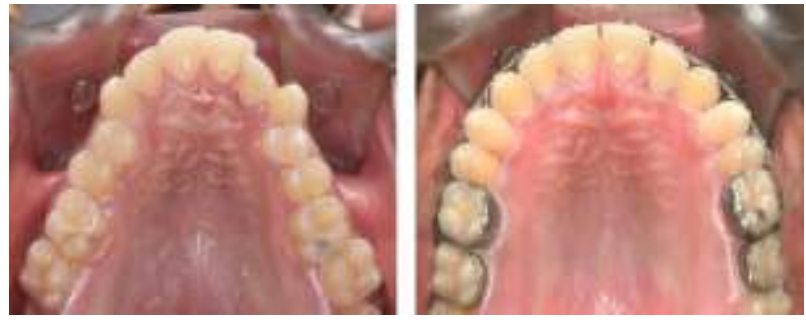

Fig 10. Pre and Post expansion comparison

\section{DISCUSSION}

It is challenging to treat cases with severe transverse discrepancies. To overcome difficulties associated with traditional corticotomy a rather new method of corticotomy (piezo assisted corticotomy) was chosen for the treatment. Piezocision is a minimally invasive corticotomy technique..$^{19,20,21}$ it produces less patient discomfort, trauma and lesser periodontal consequences when compared to conventional corticotomy with the same clinical outcome. ${ }^{19,21,22}$

Guidance for the surgery was done based on marking incision in the middle of two roots after OPG examination followed by piezo assisted grooving of bone. Only the areas requiring expansion ie the buccal cortex from canines to molars were chosen bilaterally to avoid any complications and anchorage loss. Additionally, the fixed appliance was activated with the jockey archwire immediately post operation to gain maximum advantage of the inflammation. The patient gave complaints of discomfort and pain in the 1st week which subdued later on. Post expansion results were stable although the patient might require retention for long while for the dentition to get accommodated into its new position. The success achieved in this case cannot be used to justify the use of this protocol in every situation, Hence its unto the clinician to use this data to expand his horizon on the applications of corticotomy in orthodontics

In conclusion, Piezocision can be used as an adjunct for the orthodontic treatment of adults who require challenging tooth movement that would be difficult to achieve by conventional orthodontics, and to overcome the side effects of conventional orthodontics. 


\section{CONCLUSION}

An adult patient with a maxillary transverse deficiency and severe crowding was successfully treated with piezo assisted corticotomy. Post expansion results were positive in addition to a short treatment period taken for expansion. The patient was also averted from the extra complexity of a surgery.

\section{REFERENCES}

1. McNamara JA. Maxillary transverse deficiency. Am J Orthod DentofacialOrthop2000;117:567-70

2. Kurol J, Berglund L. Longitudinal study and cost-benefit analysisof the effect of early treatment of posterior cross-bites in the primary dentition. Eur J Orthod1992;14:173-9.

3. Proffit WR, Fields Jr HW, Sarver DM. Contemporary orthodontics. 5th ed. St. Louis (US): Elsevier Health Sciences; 2014

4. Baccetti T, Franchi L, Cameron CG, McNamara JA Jr. Treatmenttiming for rapid maxillary expansion. Angle Orthod2001;71:343-50.

5. Betts NJ, Vanarsdall RL, Barber HD, Higgins-Barber K, Fonseca RJ.Diagnosis and treatment of transverse maxillary d e f i c i e n c y

IntJAdultOrthodonOrthognathSurg1995;10 :75-96.

6. Suri L, Taneja P. Surgically assisted rapid palatal expansion: a liter-ature review. Am J Orthod Dentofacial Orthop2008;133:290302.

7. Ataca AA, Karasub HA. Surgically assisted rapid maxillary expan-sion compared with orthopedic rapid maxillary expansion. AngleOrthod2006;76:353-9.

8. Martina R, CioffiI, Farella M, Leone P, Manzo P, Matarese G, et al.Transverse changes determined by rapid and slow maxillary expan-sion-a low-dose CTbased randomized controlled trial. OrthodCraniofac Res 2012;15:159-68.
9. Garib GD, Henriques JF. Rapid maxillary expansion-tooth tissue-borne versus toothborne expanders. Angle Orthod2005;75:548-57.

10. Gauthier C, Voyer R, Paquette M, Rompre P, Papadakis A. Peri-odontal effects of surgically assisted rapid palatal expansion eval-uated clinically and with cone-beam computerized tomography:6-month preliminary results. Am J Orthod Dentofacial Orthop2011;139(4 Suppl):S117-28.

11. Pangrazio-Kulbersh V, Jezdimir B, de Deus HaugheyM,Kulbersh R, Wine P, Kaczynski R. CBCT assessment of alveolarbuccal bone level after RME. Angle Orthod2013;83:1106.

12. Kole H. Surgical operations on the alveolar ridge to correct occlusalabnormalities. Oral Surg Oral Med Oral Pathol1959;12:515-29.

13. Converse JM, Horowitz SL. The surgicalorthodontic approach tothe treatment of dentofacial deformities. Am J Orthod1969;55:217-43.

14. Lines AP. Adult rapid maxillary expansion with corticotomy. Am JOrthod1975;67:4456.

15. Wilcko WM, Wilcko T, Bouquot JE, Ferguson DJ. Rapid orthodon-tics with alveolar reshaping: two case reports of decrowding. IntJPeriodontics Restorative Dent 2001;21:9-19.

16. Wilcko WM, Ferguson DJ, Bouquot JE, Wilcko T. Rapid orthodontic decrowding with alveolar augmentation: case report. World JOrthod2003;4:197-205.

17. Wilcko MT, Wilcko WM, Pulver JJ, Bissada NF, Bouquot JE. Accelerated osteogenic orthodontics technique: a 1-stage surgicallyfacilitated rapid orthodontic technique with alveolar augmenta-tion. J Oral MaxillofacSurg2009;67:2149-59. 
18. Accelerated orthodontic tooth movement procedure. In: Federico Brugnami, Alfonso Caiazzo., editors. Orthodontically Driven Corticotomy: Tissue Engineering to Enhance Orthodontic and Multidisciplinary Treatment. NJ (USA): Wiley-Blackwell; 2014. p. 119. [Google Scholar]

19. Echchadi, M. E., Benchikh, B., Bellamine, M., \& Kim, S.-H. (2015). Corticotomyassisted rapid maxillary expansion: A novel approach with a 3-year follow-up. American Journal of Orthodontics and Dentofacial Orthopedics, $\quad 148(1)$, 138-153.doi:10.1016/j.ajodo.2014.08.023

20. Sebaoun JD, Surmenian J, Dibart S. Traitementsorthodontiquesaccélérés par piézocision: une alternative mini-invasive aux corticotomiesalvéolaires. L'OrthodontieFrançaise. 2011;82:311-319.

22. Dibart S, Sebaoun JD, Surmenian J. Piezocision: a minimally invasive, periodontally accelerated orthodontic tooth movement procedure. CompendContinEduc Dent. 2009;30:342-344. 346, 348-3450.

23. Dibart S, Keser EI. Piezocision ${ }^{\mathrm{TM}}$. Minimally invasive periodontally 